\title{
Differentiation of MDMA or 5-MeO-DIPT induced cognitive deficits in rat following adolescent exposure
}

\author{
David M. Compton, Melissa C. Selinger, Eric Westman and Peter Otero \\ Palm Beach Atlantic University, West Palm Beach, FL, USA
}

\begin{abstract}
The so-called "club drug" Foxy or Methoxy Foxy (5-Methoxy-N,N-di(iso)propyltryptamine hydrochloride; 5-MeO-DIPT) is a newer drug of abuse that has recently gained in popularity among recreational users as an alternative to MDMA (Ecstasy). While considerable research into the consequences of MDMA use is available, much remains unknown about the neurobiological consequences of 5-MeO-DIPT use. In the present study, beginning at 35 days of age adolescent rats were given repeated injections of $10 \mathrm{mg} / \mathrm{kg}$ of 5-MeO-DIPT, MDMA, or a corresponding volume of isotonic saline. Adult animals (135 days old) were trained and tested on a number of tasks designed to assess the impact, if any, and severity of 5-MeO-DIPT and MDMA, on a series of spatial and nonspatial memory tasks. Both the 5-MeO-DIPT- and the MDMA-treated rats were able to master the spatial navigation tests where the task included a single goal location and all groups performed comparably on these phases of training and testing. Conversely, the performance of both groups of the drug-treated rats was markedly inferior to that of the control animals on a task where the goal was moved to a new location and on a response learning task, suggesting a lack of flexibility in adapting their responses to changing task demands. In addition, in a response learning version of a learning set task, 5-MeO-DIPT rats made significantly more working memory errors than MDMA or control rats. Results are discussed in terms of observed alterations in serotonin activity in the forebrain and the consequences of compromised serotoninergic systems on cognitive processes. Keywords: 5-Methoxy-N,Ndi(iso)propyltryptamine hydrochloride; Foxy, Methoxy Foxy; (+)-3,4-methylenedioxymethamphetamine, MDMA, spatial learning; response learning, morris water maze, development, memory.
\end{abstract}

Received 15 March 2011; received in revised form 22 April 2011; accepted 21 May 2011. Available on line 15 June 2011

\section{Introduction}

A number of reports have suggested that $( \pm)$ 3,4-metylenedioxymethamphetamine (MDMA) use in humans is associated with a variety of impairments including alterations to working memory or prospective memory, as well as alterations in executive functioning (Fox, Toplis, Turner, \& Parrott, 2001; Heffernan, Jarvis, Rodgers, Scholey, \& Ling, 2001; Heffernan, Ling, \& Scholey, 2001; Wareing, Fisk, \& Murphy, 2000). In addition, at least some of the observed memory impairments may actually be a result of a general problem in the ability to attend to relevant environmental events rather than a deficit in memory storage (Parrott \& Lasky, 1998). Last, declines in measures of executive function and decision-making skills do not appear to improve after abstinence from

David M. Compton, Selinger, Eric Westman and Peter Otero, Department of Psychology. Palm Beach Atlantic University, FL, USA. Melissa C. Selinger, Department of Pharmaceutical Sciences, Palm Beach Atlantic University, FL, USA. Correspondence regarding this article should be directed to: David M. Compton, Palm Beach Atlantic University, Department of Psychology, PO Box 24708, West Palm Beach, Florida 33416-4708, USA Email: david_compton@pba.edu
MDMA (Zakzanis \& Campbell, 2006). Consistent with these findings, in research involving the use of animal models, a number of learning and memory impairments after MDMA exposure have been reported (Able, Gudelsky, Vorhees, \& Williams, 2006; Arias-Cavieres et al., 2010; Sprague, Preston, Leifheit, \& Woodside, 2003; Vorhees, Reed, Skelton, \& Williams, 2004; Vorhees, Schaefer, \& Williams, 2007; Vorhees et al., 2009).

Exposure to MDMA produces reductions in brain serotonin levels (Skelton et al., 2008) and this effect has been observed in both human as well as nonhuman primates and in rats (see Green, Mechan, Elliott , O'Shea, \& Colado, 2003, for a review). Serotonin reductions are seen in a number of regions involved in different types of learning and memory, including the prefrontal cortex, hippocampus and the dorsal striatum (Skelton et al., 2008) in adult rats (Able et al., 2006) as well as rats exposed when they are young (Vorhees et al., 2004; Vorhees et al., 2007; Vorhees et al., 2009). Past research has indicated that the memory deficits involve a reference memory impairment (Sprague et al., 2003), although the tasks employed did not allow for differentiation between working and reference memory deficits (Kay, Harper, \& Hunt, 2010). However, in one recent investigation (Kay et al., 2010) designed to 
more precisely define the nature of the memory deficit, MDMA disrupted reference memory for the rules to successfully solve an eight-arm radial maze task.

The neurotoxic effects of MDMA exposure appear rapidly (Schmidt, 1987) and are well-documented (see Lyles \& Cadet, 2003). As noted earlier, a number of investigators have found acute reductions in serotonin (5HT) or the 5-HT metabolite 5-HIAA levels in regions of the rodent brain associated with a variety memory processes, including the prefrontal cortex, areas of the striatum, and hippocampus (Battaglia et al., 1987; Battaglia, Yeh, \& De Souza, 1988; De Souza, Battaglia, \& Insel, 1990; Slikker et al., 1988). Such alterations in 5-HT function have been reported to continue long after exposure to MDMA (Battaglia et al., 1987; Fischer, Hatzidimitriou, Wlos, Katz, \& Ricaurte, 1995; Hatzidimitriou, McCann, \& Ricaurte, 1999; Lew et al., 1996; Scanzello, Hatzidimitriou, Martello, Katz, \& Ricaurte, 1993).

Like other hallucinogenic drugs popular among teenagers and young adults who frequent the socalled club scene or raves, 5-Methoxy-N,N-di(iso) propyltryptamine hydrochloride (5-MeO-DIPT) better known as Foxy or Methoxy Foxy has gained in popularity among recreational users. 5-MeO-DIPT has properties similar to other tryptaminergic hallucinogens (Shulgrin \& Carter, 1980) and these properties have led recreational users of MDMA and other similar compounds to experiment with this drug. Because of its similarity to other tryptamine compounds that have been abused and reports of the negative consequences of Foxy abuse (e.g., Ikeda, Sekiguchi, Fujita, Yamadera, \& Kog, 2005; Wilson, McGeorge, Smolinske, \& Meatherall, 2005), in the United States MeO-DIPT was classified as a Schedule I drug (United States Drug Enforcement Administration, 2003). Unfortunately, although some recent work has elucidated some of the effects of this compound (Compton, Dietrich, Selinger, \& Testa, 2011; Compton, Selinger, Testa, \& Larkins, 2006; Ikeda et al., 2005; Skelton et al., 2009; Wilson et al., 2005), our knowledge of the consequences associated with the use of MeO-DIPT on neuropsychological development or behavior remains limited.

According to Tirelli, Laviola, and Adriani (2000), adolescence in rats lasts from the 21st postnatal day (PND) following birth until PND 60. Within this period of development, mid adolescence includes PND 34 to 46 and late adolescence from PND 46 to 59. These two periods can be considered as analogous to periadolescence and late adolescence/early adulthood, respectively (Tirelli et al., 2000). According to Spear (2000), this rodent model is useful for both comparative evaluations and for extrapolation to humans. Thus, the use of adolescent animals provides a valuable experimental framework for examining the developmental consequences associated with drugs of abuse at various points in biological and cognitive development.
Unlike MDMA, much less is known about the specific effects and the long-term consequences associated with the use of 5-MeO-DIPT. Certainly, given the previous reports about the consequences associated with its use (Ikeda et al., 2005; Wilson et al., 2005 ) and the toxicological investigations (Meatherall \& Sharma, 2003; Sitaram, Lockett, \& Blackman, 1987; Smolinske, Rastogi, \& Schenkel, 2003), further consideration of the effects of this drug is warranted. Indeed, attention has only recently turned to the specific central nervous system effects of $5-\mathrm{MeO}-$ DIPT (Compton et al., 2006, 2011; Nagai, Nonaka, Satoh, \& Hisashi, 2007; Nakagawa \& Kaneko, 2008; Skelton et al., 2009;). Of the published investigations, only a select few (e.g., Compton et al., 2006; Skelton et al., 2009) have explored the long-term consequences associated with exposure at different points in brain development. As the availability and popularity may increase, the possible risks to development in vulnerable adolescents may be seen as an emerging societal health problem. Thus, understanding the consequences of developmental exposure to $5-\mathrm{MeO}$ DIPT on physiology, learning, and memory may be important because as the use of 5-MeO-DIPT increases so, too, may the consequences.

\section{Methods}

\section{Subjects}

The subjects consisted of 21 male experimentally naive Long-Evans rats bred in the vivarium at Palm Beach Atlantic University. The research protocol was reviewed and approved by the Institutional Animal Care and Use Committee of Palm Beach Atlantic University and the animals were treated in accordance with the principles of animal care outlined in the Guide for the Care and Use of Laboratory Animals (National Research Council, 1996). Drug exposure began when the rats were in the mid-adolescent period of development (i.e., 35 days old). The animals were exposed to a total of six injections, spaced 48 hours part. Thus, the rats were exposed to 5-MeO-DIPT, MDMA, or saline from 35 to 46 days of age. The rats were individually housed, maintained on a 12-hr light/12-hr dark cycle with the lights on at 7:00 am. All animals were provided with ad lib access to food (Mazuri Rodent Chow) and water.

\section{Drug and drug administration}

All rats received a total of six injections of 5-MeODIPT $(10 \mathrm{mg} / \mathrm{kg}$; Biosynth International, Naperville, IL), MDMA (10 mg/kg; Sigma-Aldrich, St. Louis, MO), or a corresponding injection volume of isotonic saline. Purity of the 5-MeO-DIPT and MDMA was verified by the suppliers using HPLC. During the period of all drug exposure sessions, the ambient temperature as maintained at $25^{\circ}{ }_{\mathrm{C}}$ with the humidity between $45 \%$ and $50 \%$. 
In order to provide a rough approximation of the effects associated with multiple party "rave" experiences, a 48 hour injection period was chosen. However, it should be noted that products sold as Ecstasy often contain other synthetic compounds including piperazines (BZP and other piperazines, 2010) and that the proportion of other compounds relative to MDMA have increased in recent years (World Drug Report [WDR], 2010). Less information is available about the specific properties of drugs sold as 5-MeODIPT. Acknowledging this, the protocol was intended to compare the developmental consequences of each compound rather than replicate exactly the consumption of these compounds among adolescent humans. Here, our goal was to assess the developmental consequences of adolescent exposure following repeated exposure during a critical period in brain development and assess the effects and associated possible risks.

All injections were delivered IP. According to the United States Drug Enforcement Administration, the principle effects of 5-MeO-DIPT persist for periods ranging from 3 to 6 hours with peak effects occurring at least one hour after exposure (Drugs and chemicals of concern, 2009). Further, while data about the halflife 5-Meo-DIPT is still somewhat limited, a 48 hour exposure window seemed acceptable. In one recent report (Kanamori, Kuwayama, Tsujikawa, Miyaguchi, \& Kishi, 2006), analysis of 24-48 hour urinary fractions suggested that 5-Meo-DIPT as well as its metabolites are rapidly eliminated, at least in rats. The authors report that only the metabolite 5-OH-DIPT was detected, albeit as a small quantity of $0.4 \%$ (Kanamori et al., 2006). More information is known about MDMA (Kalant, 2001; Mas et al., 1999; Verebey, Alrazi, \& Jaffe, 1988). For example, in humans, the elimination half-life of MDMA is 7.7 hours for low doses and 8.6 hours for high doses (Mas et al., 1999).

\section{Apparatus}

The rotating rod test to assess general motor deficits.

The rotating rod test consisted of a rotating wooden dowel (10 cm in circumference \& $162 \mathrm{~cm}$ long) wrapped with tape to help prevent the rat from slipping and elevated $100 \mathrm{~cm}$ above the floor. An electric motor rotated the wooden at a speed of five rotations per minute. Approximately $20 \mathrm{~cm}$ of foam padding was placed beneath the apparatus to prevent injury in case a rat fell.

\section{Morris water maze (MWM)}

With the exception of the number of trials in goal rotation testing, all spatial testing was similar to that described by Compton, Dietrich, and Smith (1997) and occurred in a circular white acrylic plastic swimming pool $183 \mathrm{~cm}$ in diameter. Water was filled to a depth of $30 \mathrm{~cm}$ and made opaque by the addition of a nontoxic paint (Sargant Art, Hazelton, PA). The pool was located in a testing room approximately 36.88 square meters in size, with a number of external stimuli visible from the surface of the pool. A $15 \mathrm{~cm} \mathrm{X} 15 \mathrm{~cm}$ escape platform painted flat white was located $18 \mathrm{~cm}$ from the wall of the swimming pool and submerged a depth of $1 \mathrm{~cm}$ below the surface of the water. During constant-start training and novel-start testing, the escape platform was located in the northwest quadrant. The platform was relocated to the southeast quadrant for goal rotation testing.

\section{Greek cross response testing}

The circular water tank described above and fitted with galvanized steel partitions to form alleys (see Figure 1), served as the apparatus for the Greek cross response training. Each alley of the cross measured $57.15 \mathrm{~cm}$ X $27.94 \mathrm{~cm}$.

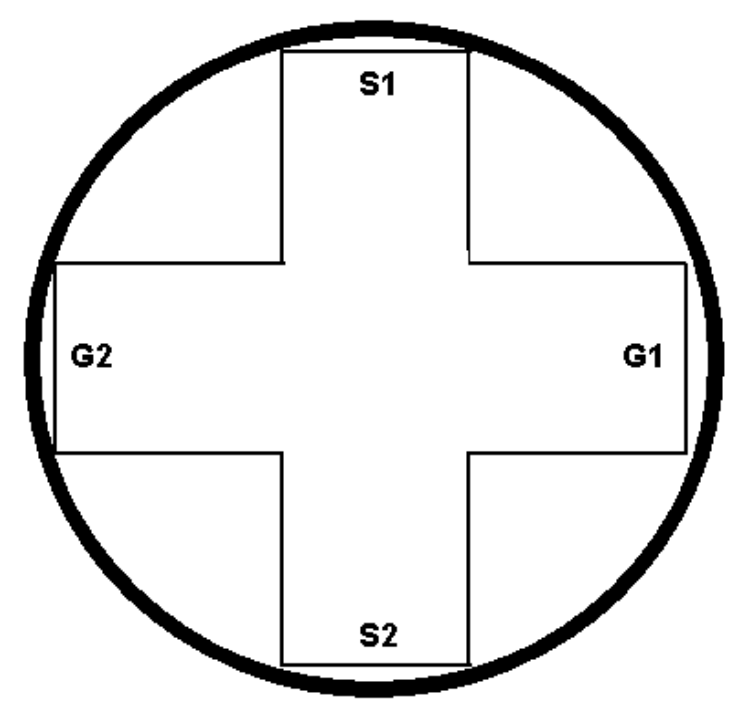

Figure 1. A schematic representation of the apparatus. $\mathrm{S}=$ start locations; $\mathrm{G}=$ escape locations.

\section{Procedure}

Behavioral testing began when the rats were 135 days of age. First, the animals were assessed for general motor coordination and activity levels. Immediately following these two tests, all animals were trained or tested in the following test order - constant start training, novel start testing, goal rotation testing, and Greek cross response learning.

\section{Assessment of general motor ability}

The electric motor was turned on for one minute before the beginning of the assessment to allow the rat time to acclimate to the sound of the electric motor. An assessment began when the rat was placed onto the rod and the experimenter verified that all four feet were securely placed on the rod. Following this, the electric motor was switch on and the number of slips and falls in a one minute period were recorded. Slips were scored whenever the rat fell partially off of the rod but was 
still able to hold on for one rotation. Falls were scored whenever the rat completely fell completely off of the rod onto the foam. When a rat slipped or fell, it was immediately repositioned on the actively rotating rod.

\section{Spatial learning and testing}

During the constant-start phase of training, the starting position, location of the platform, and all extra-maze cues remained fixed. Under conditions with constant start and escape loci, memory demands for the representation of multiple positional relationships are unnecessary for timely successful escapes to the swim platform (Eichenbaum, Stewart, \& Morris, 1991). Therefore, it was predicted that both the saline- and the drug-treated animals would learn the location of the platform.

In the second phase of the experiment, the novel start phase, rapid escape to the platform required the flexible use of cues (Eichenbaum et al., 1991). Therefore, some impairment on novel-start trials was predicted because the animal must be able to understand where the new starting location is located relative to the escape platform. This involves an understanding that the cues in the environment have changed relative to their own position and transpose their own understanding of where to swim relying on such a change in allocentric cues (Cohen \& Eichenbaum, 1993; Eichenbaum et al., 1991). Finally, the goal rotation phase involved multiple starting locations and movement of the escape platform to a new location opposite of its former location. Here, in order to successfully navigate the maze and locate the escape platform in a timely manner, the animal must recall of multiple positional relationships among the available extra-maze cues.

\section{Constant-start training}

The initial phase of Morris water maze training consisted of four daily trials with a single start and a single escape location. The platform was located in the Northwest quadrant at a distance of $15 \mathrm{~cm}$ from the wall of the swimming pool. All animals began each trial facing the inner wall at the North end of the pool. On any given trial, if a rat failed to find the escape platform within 60 seconds, it was gently lifted from the water and placed on the platform. On all trials, the animals were permitted to remain on the platform for a 15 second rest period. The animals were trained until they were able reach the escape platform in less than 10 seconds on three out of four daily trials for two consecutive days.

\section{Novel-start testing}

Testing in the novel-start phase consisted of three 6-trial sessions. Each day, trials one, two, four, and five were identical to constant-start trials described above. Within each daily session, the third and sixth trial of the day involved one of six novel-start locations. During this phase of testing, each novel start location was presented once in the following order-southeast, west, northeast, southwest, south, and east. With the exception of the novel-start locations, the procedure was identical to that described in constant-start training.

\section{Goal rotation testing}

For the purpose of goal rotation testing, the platform was moved from its former location in the northwest quadrant to a new position $180^{\circ}$ from the former position (i.e., the southeast quadrant). Testing in this phase consisted of five 4-trial sessions that began in the north, south, east, or west quadrants. The remainder of the procedure was identical to that described in constant-start training.

\section{Nonspatial assessment}

In the Greek-cross response learning task used in the present investigation, the animal was faced with three response alternatives, to turn right, to turn left, or to swim straight ahead. The configuration of the available allocentric information differs depending on the start location both within individual trials and across reversals (McDaniel et al., 1995). The correct behavioral response (i.e., "turn left" vs. "turn right") depends on first learning a rule to turn in a specific direction regardless of the start location and then, when the goal position is changed, to turn in the opposite direction if, having turned the opposite way the animal finds the platform in a new location. Here, too, the rat must learn to turn in the opposite direction after a nonrewarded (but formerly rewarded) trial. Thus, the Greek-cross task may be considered especially sensitive to the behavioral flexibility of the animal (McDaniel et al., 1995). Because of the reversal requirement, the inability to flexibly adjust behavior as function of changing environmental and behavioral demands should be reflected in perseverative behavior (see Clarke, Robbins, \& Roberts, 2008).

\section{Greek cross response testing}

At the beginning of each trial, the rat was placed in the water facing the exterior wall of the start alley. For each trial, one of the two possible starting locations were randomized and the order of the start or goal positions (see following) were determined through the use of a Fellows series (Fellows, 1967). The task involved learning a specific turning response as well as a win-stay, lose-shift rule. Thus, the task was designed to assess nonspatial response learning as well as working and reference memory errors. The escape platform was located at one of two possible goal positions and the animals started at one of the two possible starting positions, depending on whether the animal was currently trained to turn right or left. Animals received 10 training trials per day, with a rest interval of 20 seconds between trials. Successful mastery of the rule was defined as 9 errorless responses within a given daily 
session consisting of 10 trials and an error was defined as entry of the head and abdomen into either of the current two incorrect alleys or premature exit from the correct alley. The animals were permitted to self-correct for errors and to explore the apparatus and locate the platform.

In addition to the consideration of the total number of errors, errors were subdivided into reference and working memory errors in a manner consistent with the existing literature (e.g., Kesner, DiMattia, \& Crutcher, 1987; McDaniel et al., 1995). Specifically, the initial entries into incorrect alleys were defined as reference memory errors while re-entry to inaccurate alleys was defined as working memory errors.

On each trial, if an animal failed to locate the escape platform within 60 seconds it was placed on the platform for about 15 seconds. After criterion was achieved for a given turning response, either right or left, the escape platform was moved to the end of the opposite alley (i.e., $180^{\circ}$ ) from the previously correct alley. If an animal failed to achieve the criterion within 100 trials, the platform was moved to the opposite goal location. Testing continued until the animals mastered the criterion described earlier on 10 response position reversals.

\section{Assessment of brain serotonin (5-HT) levels}

Fourteen days after the completion of all behavioral data collection, all animals were euthanized for the assessment of brain serotonin (5-HT) levels. The 5-HT levels were established in the 5-MeO-DIPT, MDMA, and control animals using high performance liquid chromatography (HPLC; Waters Model 600 with electrochemical detection). The procedure was based on a modified version of that described by Chapin, Lookingland, and Moore (1994). Using Millennium32 software (Waters, Milford, MA), the raw data were integrated and analyzed to determine 5-HT levels in hippocampus, striatum, and the prefrontal cortex. Concentrations in the amounts of $0.04 \%$ sodium octyl sulfate, $0.1 \mathrm{mM}$ disodiumethylenediamine-tetraacetate, $0.05 \mathrm{M}$ sodium phosphate were dissolved in HPLCgrade $\mathrm{H}_{2} 0$ with $0.03 \mathrm{M}$ citric acid as a buffer. The aqueous portion of the mobile phase was maintained at $\mathrm{pH}$ levels between 2.7 and 2.9. The mobile phase consisted of $20 \%$ methanol and $80 \%$ aqueous phase. The HPLC column was a Waters $\mathrm{C}_{18}$ reverse phase analytical column ( 3.9 X $300 \mathrm{~mm} ; 4 \mu \mathrm{m})$. Serotonin levels were calculated and reported as $n g / g$ tissue.

\section{Results}

\section{Assessment of general motor ability}

An ANOVA was used to explore the possible effect of the drug on motor performance (results are not shown). Although the groups did better across assessments, no drug associated effects were found suggesting that neither MDMA nor 5-MeO-DIPT impaired gross motor function.
Spatial learning and testing - constant-start training

The learning ability of the rats during the initial phase of training was examined by analyzing the first 8 training trials and the last 4 training trials associated with the criterion (see Method section). Using the swim time to the escape platform as the dependent measure, the data were analyzed using a 1-Between (3-drug groups), 1-Within (12 trials) analysis of variance (ANOVA; results are not shown). Swim times to the escape platform decreased as a function of training for all animals, $F(2,42)=108.95 ; p<.001$. The main effect of drug group and the drug group $\mathrm{X}$ trials interaction were nonsignificant. At the end of constant-start training, swim times for all three drug conditions were comparable. Last, the number of trials through the criterion of three out of four trials under 10 seconds for two consecutive days was comparable across all three groups.

\section{Novel-start testing}

In order to allow for direct comparison of swim latencies across start locations with considerably different minimum swim path distances, the recorded escape latencies for each novel start location were normalized. Normalization was accomplished by computation of the ratio of the minimum swim distance in centimeters for each novel start location to the minimum swim on regular (i.e., constant start) trials in centimeters. Assessment of the impact of starting the animals from a new location was accomplished by averaging the swim times for the trials preceding the novel-start trials. The resulting times were compared to the average of all of the novel-start test trials and are presented in Figure 2.

Analysis of the resulting data with a 1-Between (3drug group), 1-Within (i.e., constant-start vs. novel-start locations) ANOVA produced a main effect of constant-

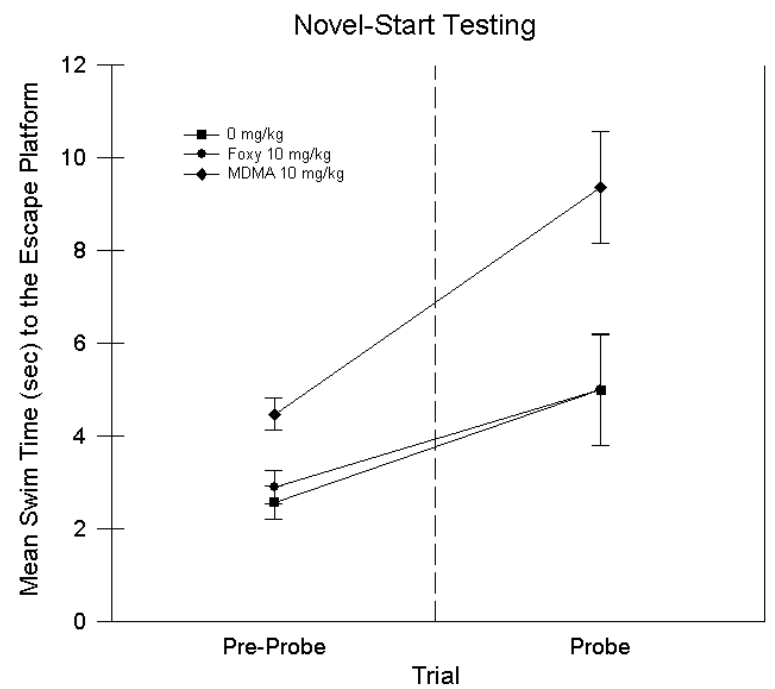

Figure 2. Mean escape latencies across novel-start (test) trials. The mean escape latencies on regular (i.e., constantstart) trials that preceded the test trials were collapsed and compared to the mean escape latencies collapsed across the six novel-start loci. Vertical lines represent the standard error of the mean $(S E M)$. 
start versus novel-start test trial performance, $F(1,21)$ $=17.68 ; p<.001$, suggesting that changing the start location disrupted the navigation performance of the animals. Further, a main effect of drug group was found, $F(2,21)=8.41 ; p<.01$. Closer examination of the drug effect indicated that MDMA-treated animals took significantly longer than 5-MeO-DIPT-treated or control animals to find the platform. Nonetheless, the Drug Group X Start Location interaction was nonsignificant.

\section{Goal rotation testing}

For the assessment of the goal rotation data, the four daily trials were normalized and averaged and navigation performance was assessed over a five-day period. Using a 1-Between, 1-Within (5 days) ANOVA, the analysis revealed main effects of the drug treatment, $F(2,21)=9.94 ; p<.001$, and test days, $F(4,84)=54.10$; $p<.001$, suggesting that group swim times differed and that the swim times decreased significantly across the five-day test period.

As can be seen in Figure 3, a significant drug group $\mathrm{X}$ test days interaction was detected, $F(8,84)=3.61 ; p$ $<.05$, suggesting that, while all three groups improved across test days, the reduction in escape latencies occurred at different rates. Post hoc comparisons indicated that the saline control rats found the platform significantly faster than the MDMA-treated rats on the first and last days of goal rotation testing. Initially, swim times for the 5-Meo-DIPT-treated rats were higher than that of the control rats. However, this response difference was resolved by the second day of testing.

Assessment of nonspatial learning and memory - Greekcross response training

The mean proportion of correct responses across reversal training for the first 10 trials per reversal is

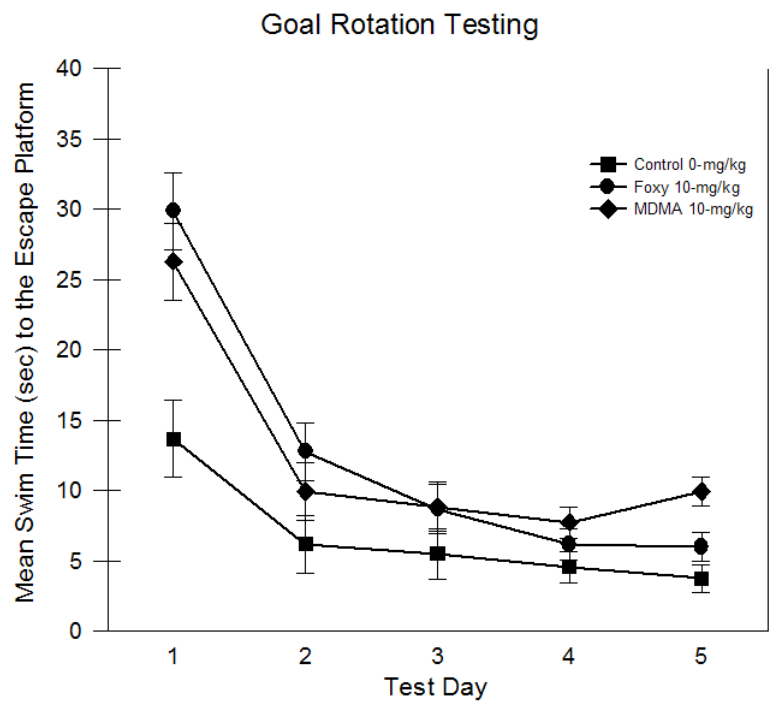

Figure 3. Daily mean escape latencies across the 20 goal rotation test trials. Vertical lines represent SEM. presented in Figure 4. A 1-Between, 1-Within (10 Reversals) ANOVA revealed the following. The main effect of drug condition was significant, $F(2,21)=18.31 ; p$ $<.001$, suggesting a drug-related effect on the proportion of errorless trials following a response reversal. A main effect of reversal was also found, $F(9,189)=23.65 ; p<.001$, suggesting that the performance of the rats improved as a function of experience with the task.

However, as suggested in Figure 4, a drug group X reversal interaction, $F(18,189)=2.79 ; p<.001$, was present suggesting that the performances of the control and drugtreated rats differed across training. Post hoc comparisons

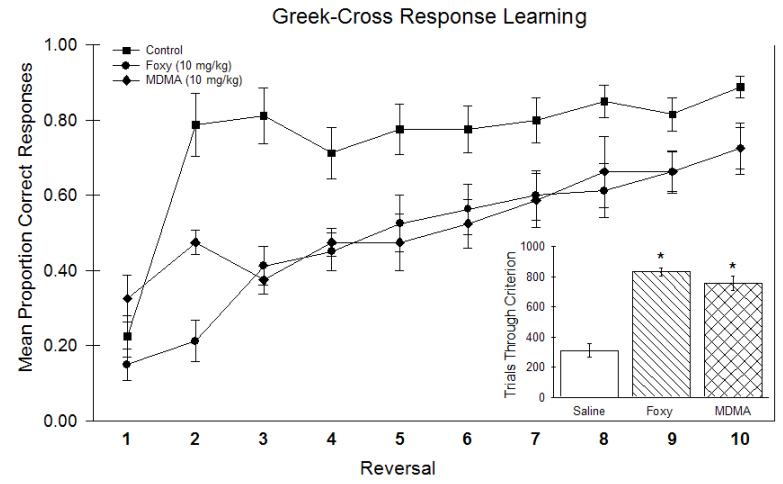

Figure 4. Response accuracy on the first 10 trials following a reversal across the 10 response learning reversals. Vertical lines represent SEM.

indicated that, with the exception of the $8^{\text {th }}$ and $10^{\text {th }}$ reversals, the performance of the saline-treated rats was superior to that of both the 5-MeO-DIPT-and MDMA-treated rats. Further, with the exception of the $2^{\text {nd }}$ reversal, no differences between the two drug groups were detected. Consistent with these observations, both drug groups required significantly more trials to achieve the criterion than the saline-treated rats (see inset of Figure 4). Consistent with above, the two drugtreated groups did not differ.

In addition to the results reported above, the total number of errors across training was considered. All errors were scored as either reference or working memory errors (Kesner et al., 1987; McDaniel et al., 1995). Reference memory errors were scored whenever an animal entered an incorrect alley. Working memory errors were defined as re-entries into incorrect alleys. In the Greek cross task, because a given alley has previously been explored within the trial, working memory errors as defined here are indicative of perseverative behavior.

Examination of the error data presented in Figure 5 revealed the following. Consistent with the trials through criterion measure, the total number of errors (Figure 5 c) differed as a function of drug group, $F(2,21)=$ 48.96; $p<.001$. Post hoc examination indicated that the control rats made significantly less errors than the two drug groups, which did not differ significantly. When working memory errors were considered, a main effect of drug group was found, $F(2,21)=163.38 ; p<.001$, and 
post hoc comparisons produced an expected difference between the control and drug-treated rats. In addition and of considerable import, 5-MeO-DIPT treated rats made significantly more working memory errors than MDMAtreated rats (see Figure 5a). An effect of drug group on reference memory errors was also found, $F(2,21)=$ 31.99; $p<.001$. However, the two drug-treated groups differed only from the control rats (Figure $5 b$ ).

\section{Neurochemical analysis of brain 5-HT levels}

The mean levels of 5-HT in the prefrontal cortex, striatum and hippocampus are shown in Table 1. Serotonin levels differed as a function of drug exposure in the prefrontal cortex, $F(2,21)=66.25 ; p<.001$,

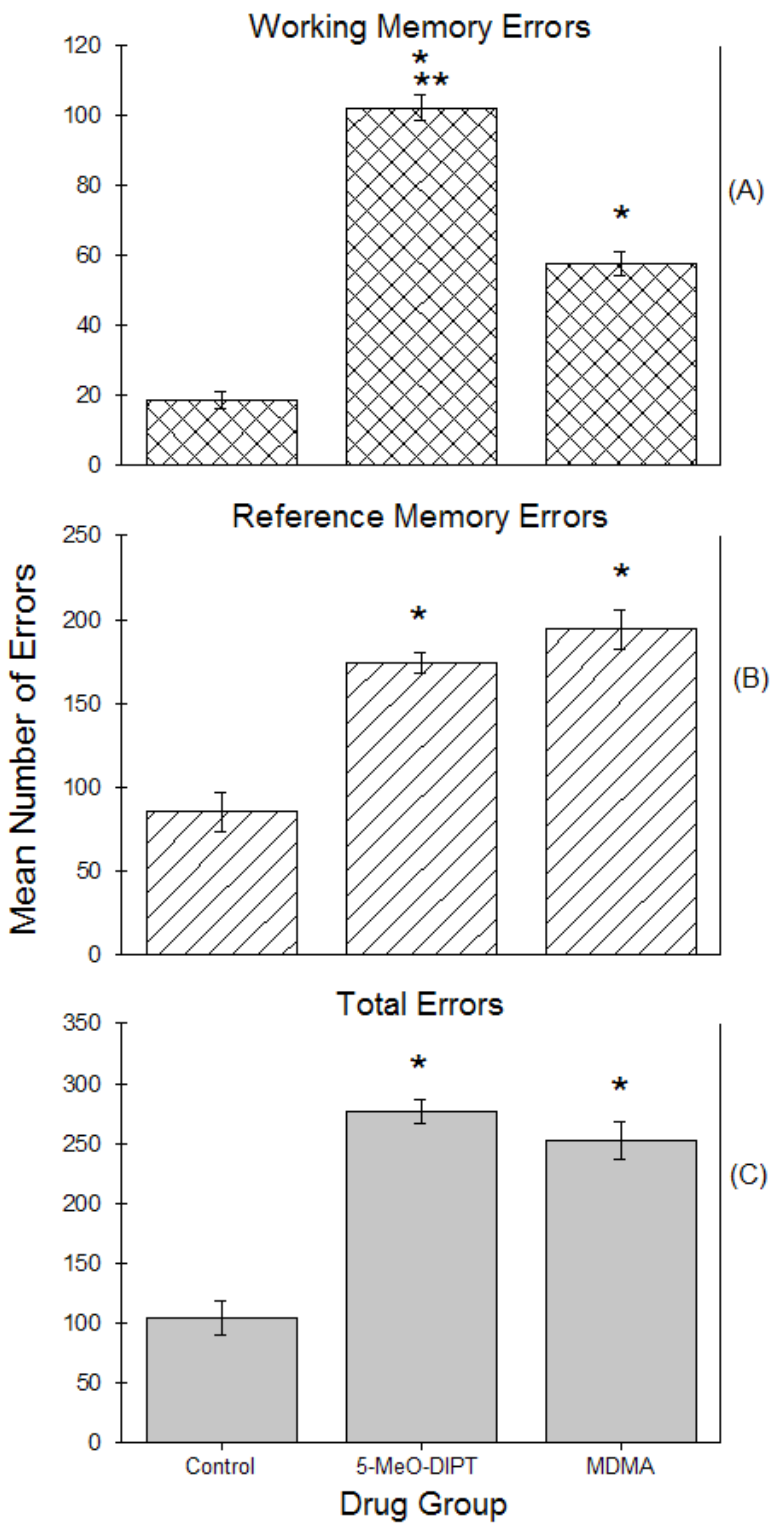

Figure 5. Bar graphs depicting the mean and standard error of the mean for (a) working memory errors, defined as re-entry errors, (b) reference memory errors, defined as initial alley entrance errors, and (c) total errors. Notes. *Significantly different from control, **Significantly different from MDMA striatum, $F(2,21)=28.24 ; p<.001$, and the hippocampus, $F(2,21)=58.93, p<.001$. Post hoc examination of these results indicated the following. When compared to the saline-treated rats, reductions in prefrontal 5-HT levels were observed in both the 5-MeO-DIPT-treated rats $(59.2 \%)$ and the MDMA-treated rats (67.3\%). However, the difference in 5-HT levels in both drugtreated groups was nonsignificant. When compared to control rats, significant reductions in striatal 5-HT were also observed (33.7\% for 5-MeO-DIPT \& $39.5 \%$ for the MDMA rats). Last, an examination of the 5-HT levels in the hippocampus indicated significant reductions in 5 -HT $(50.1 \% \& 63.8 \%)$ in both the 5-MeO-DIPT and MDMA drug groups. However, when the two drug groups were compared, once again the 5-HT levels were comparable (i.e., $p>.05$ ).

On the basis of the results described above, a series of stepwise regression analyses were performed, with the 5-HT levels in the prefrontal cortex, striatum, and the hippocampus serving as predictor variables. Each predictor variable was entered separately with the order

Table 1. Mean levels of 5-HT in the prefrontal cortex, striatum, and hippocampus of saline-, 5-MeO-DIPT-, or MDMA-treated rats

\begin{tabular}{|c|c|c|c|}
\hline Drug group & $\begin{array}{l}\text { Prefrontal } \\
\text { cortex } \\
M(S D)\end{array}$ & $\begin{array}{l}\text { Striatum } \\
M(S D)\end{array}$ & $\begin{array}{l}\text { Hippocampus } \\
M(S D)\end{array}$ \\
\hline $\begin{array}{l}\text { Saline-treated } \\
\text { rats }\end{array}$ & $\begin{array}{c}141.42 \\
(21.55)^{*}\end{array}$ & $\begin{array}{c}189.04 \\
(18.01)^{*}\end{array}$ & $\begin{array}{c}128.77 \\
(21.58)^{*}\end{array}$ \\
\hline $\begin{array}{l}\mathrm{MeO}-\mathrm{DIPT}- \\
\text { treated rats }\end{array}$ & $\begin{array}{l}57.67 \\
(16.24)^{*}\end{array}$ & $\begin{array}{c}125.39 \\
(22.95)^{*}\end{array}$ & $\begin{array}{l}63.17 \\
(16.24)^{*}\end{array}$ \\
\hline $\begin{array}{l}\% \text { Difference } \\
\text { from controls }\end{array}$ & - 59.2 & - 33.7 & - 50.1 \\
\hline $\begin{array}{l}\text { MDMA- } \\
\text { treated rats }\end{array}$ & $\begin{array}{l}46.29 \\
(15.79)^{*}\end{array}$ & $\begin{array}{l}114.38 \\
(23.02)^{*}\end{array}$ & $\begin{array}{l}446.55 \\
(6.32)^{*}\end{array}$ \\
\hline $\begin{array}{l}\% \text { Difference } \\
\text { from controls }\end{array}$ & - 67.3 & - $\quad 39.5$ & - $\quad 63.8$ \\
\hline
\end{tabular}

Notes. Means and standard deviations are expressed in $n g / g$ tissue. $*(\mathrm{p}<.05)$.

of each variable determined on the basis of bivariate correlations. The drug-related deficits were observed in two tasks, goal rotation testing and Greek cross response learning. Therefore, swim performances on the goal rotation task and the trials through criterion, reference memory errors, and the working memory errors measures of the Greek cross task were chosen as the dependent measures. The results of the stepwise regression analyses were as follows. 
In order to further explore the effect of brain 5-HT levels on goal rotation testing, swim times were collapsed across the five days of testing. For goal rotation testing, 5-HT levels were predictive of performance accounting for $62.7 \%$ of the variance in swim times. However, only the standardized regression coefficient $(\beta)$ associated with hippocampal 5-HT levels was significant $(\beta=-.622)$.

Examination of the trials through criterion measure of Greek cross response learning indicated that collectively 5-HT levels in the prefrontal cortex and the hippocampus accounted for $89.6 \%$ of the variance associated with performance on this task. Both the 5-HT levels in the prefrontal cortex $(\beta=-.548)$ and the striatum $(\beta=-.425)$ made significant contributions to the equation. Conversely, the contribution of hippocampal 5-HT levels was nonsignificant and excluded from the final equation.

Consideration of the impact of brain 5-HT levels on Greek cross working and reference memory errors revealed the following. Hippocampal $(\beta=-.393)$ and prefrontal cortex $(\beta=-.481)$ 5-HT levels both made significant albeit somewhat different contributions to the equation $\left(R^{2}=63.0 \%\right)$, but the contribution of striatal 5-HT levels was nonsignificant. When reference memory errors were considered, both striatal $(\beta=-.556)$ and prefrontal $(\beta=-.434)$ cortical 5-HT levels made significant contributions to the equation, collectively account for $77.6 \%$ of the variance. Once again, the impact of hippocampal 5-HT levels was nonsignificant.

\section{Discussion}

The effects associated with MDMA use are well known (see Lyles \& Cadet, 2003 for a review). A number of cognitive deficits associated with MDMA exposure have been reported including path integration learning deficits in the Cincinnati Water Maze (Skelton et al., 2008) and an increase in reference errors in an eight-arm radial maze (Kay et al., 2010). In humans, deficits in prospective memory (Hefferman et al., 2001), verbal memory (Fox et al., 2001), visuospatial memory (Wareing, Murphy, \& Fisk, 2004) and working memory (Wareing, et al., 2000) have been observed in MDMA users.

MDMA exposure can result in long-term impairments to cognition, including executive control, cognitive impulsivity, the ability to plan effectively, perseveration, and deficits in working memory (Marston, Reid, Lawrence, Olverman, \& Butcher, 1999; McCardle, Luebbers, Carter, Croft, \& Stough, 2004; Moyano, Frechilla, \& Del Rio, 2004; Parrott, 2002; Skelton, Williams, \& Vorhees, 2006; Skelton et al., 2009; Thompson et al., 2009; Wareing et al., 2004). Among the documented impairments is a dysfunction of working memory processes, including spatial working memory (Fox et al., 2002; Harper, Wisnewski, Hunt, \& Schenk, 2005; Wareing et al., 2000). To some extent, this appears to be dependent on prior experiences, as there have been reports of a deficit in reference memory but not in working memory (Vorhees et al., 2004).

In addition, the present MDMA results are consistent with those reported by Kay, Harper, and Hunt (2011). In the Kay et al. investigation, Sprague-Dawley rats were exposed to a single drug binge experience consisting of four injections of MDMA with an inter-injection interval of two hours. The dose of $10 \mathrm{mg} / \mathrm{kg}$ was identical to that used in the present investigation although here, we spaced the injections over six 48 hour intervals. In addition, the rats in the Kay et al. study were approximately 120 days of age while the rats used here were considerably younger. With these caveats in mind, the rats in both investigations were able to master the task at levels comparable to that of control rats but did show a definitive learning and impairment and impaired responding in the reversal phase of both experiments. However, unlike the elevated levels in working memory errors seen in the Greek cross task employed here, the MDMA-treated rats in the Kay et al. study appeared to have primarily a reference memory impairment. One reason for the inconsistency may be the differences between the elements of the two reversal tasks employed in each study. Nonetheless, the results from both studies suggest a cognitive deficit reflected in perseverative errors and after a considerable post-drug interval.

Reports from a number of investigators (e.g., Hatzidimitriou et al., 1999; Fischer, et al., 1995; Seiden, Lew, \& Malberg, 2002) suggest that the use of MDMA has the potential to produce a long-term disruption in cortical 5-HT function. Significant decreases in 5-HT has been reported months after MDMA exposure (Fox et al., 2002; Gouzoulis-Mayfrank, Thimm, Rezk, Hensen, \& Daumann, 2003; Sabol, Lew, Richards, Vosmer, \& Seiden, 1996; Scanzello et al., 1993). As such, it has been suggested that MDMA may indeed be a 5-HT neurotoxin following chronic exposure (Clemens, Cornish, Hunt, \& McGregor, 2007), although there have been reports of behavioral deficits following prenatal exposure in the absence of changes to 5-HT neurochemistry (Kelly, Ritchie, Quate, McBean, \& Olverman, 2002; Koprich et al., 2003).

Further examination of the physiological effects of 5-MeO-DIPT is warranted. Past research has demonstrated that this compound binds with the monoaminergic transporter protein SERT blocking 5-HT reuptake (Sogawa et al., 2007; see also, Murphy et al., 2008) but does not stimulate release of 5-HT (Nagai et al., 2007; Nakagawa \& Kaneko, 2008; Skelton et al., 2009). Transport of 5-HT by the SERT protein terminates the action of serotonin and recycling 5-HT in a sodium-dependent manner (Squire et al., 2003). According to Sogawa et al. (2007), the serotonergic effects associated with 5-MeO-DIPT are the result of its action as a competitive SERT inhibitor. However, unlike transportable inhibitors such as another drug 
of abuse, methamphetamine, 5-MeO-DIPT lacks the ability to cause reverse transport, suggesting that the latter has some properties that distinguish its serotonergic actions (Sogawa et al., 2007).

While additional research is required to definitively answer questions about the physiological nature of the 5-MeO-DIPT-associated deficits reported here, the response patterns associated with the present results as well as previous reports (Compton et al., 2006; Compton et al., 2011; Skelton et al., 2009) appear to support the supposition that the response deficits implicate compromised attention and response perseveration. Response perseveration is considered an indicator of impaired cognition and is associated with the ability to switch behavior as a function of changing demands. Perseverative deficits are considered distinct from motor or motivational deficits and involve a maladaptive change in executive function (Pettenuzzo et al., 2003). Navigational deficits were observed in the goal rotation phase of the MWM and marked deficits were found in a response learning version of the Greek cross. Together, the evidence is indicative of compromised impulse control, warranting additional examination of the effects of 5-MeO-DIPT on the prefrontal cortices and, depending on task demands (Compton, 2001), such subcortical structures as the striatum or dorsal hippocampus.

Lesions of 5-HT neurons is associated with increased impulsivity in rats (Soderpalm \& Svensson, 1999) and an inverse relationship between 5-HT levels and impulsivity also reported (Soubrie', 1986). Further, in SERT knockout models, multiple reports of maladaptive perseverative responses have been reported (see Kalueff, Olivier, Nonkes, \& Homberg, 2010; Shanahan et al., 2009), including deficits in the MWM (Olivier, Cools, Ellenbroek, Cuppen, \& Homberg, 2010). Similarly, reductions in 5-HT activity are associated with impulsivity in humans (Linnoila et al., 1983; Oreland, 1993). Collectively, there is enough evidence supporting the case that 5-HT directly impacts the ability of the organism to respond in an effective manner (Buhot, Martin, \& Segu, 2000; Clarke, Dalley, Crofts, Robbins, \& Roberts, 2004; Clarke et al., 2005) on the basis of stimulus-response demands and to learn to alter behavior in response to changes in relevant contingencies (Oreland, 1993).

In the present investigation, the Greek cross task as configured served as an effective assessment of the flexibility in stimulus-response contingencies. Among other roles, the prefrontal region of the cerebral cortex is central for successful responding in the presence of changing contingencies between a stimulus and response (Kolb \& Wishaw, 2003; Uylings, Groenewegen, \& Kolb, 2003). Consistent with previous reports involving depletion of prefrontal/orbitofrontal 5-HT depletion (Clarke et al., 2004; Clarke et al., 2005), the measured 5-HT levels were predictive of the perseverative impairments on the present reversal learning task (see Results section). In addition, experimentally-induced 5-HT reductions in the cerebral cortex and striatum are associated with an enduring increase in response impulsivity (Harrison, Everitt, \& Robbins, 1997). Unfortunately, the present experiment was not designed to determine whether the observed deficits were a result of problems of cognitive flexibility or an impairment in the development of new habit contingencies. However, Borg et al. (2009) have shown that genetic variations in SERT can influence cognitive flexibility.

The main goal of the present investigation was to determine the long-term consequences of adolescent exposure of MDMA and 5-MeO-DIPT by assessing the impact of these drugs in adulthood. In previous research (Compton et al., 2011), we failed to find an effect of adolescent exposure period (mid vs. late adolescence) in a number of spatial tasks in the MWM. On MWM tasks that required the flexible use of multiple spatial cues, the performance of the rats exposed to $5-\mathrm{MeO}$ DIPT during adolescence was inferior to that of salinetreated rats. The testing order of the rats was fixed rather than counterbalanced. However, since the deficits were observed in later testing elements and especially in the Greek cross phase, test phase order did not appear to obscure any drug associated deficits.

The results reported here do differ in some respects to those reported elsewhere (Skelton et al., 2009). For example, Skelton et al. found that rats treated with 5-MeO-DIPT during postnatal days 11 through 20 when compared to control rats, were impaired in spatial learning but not in tests of spatial memory or assessment of path integration. In related work with adult rats, a path integration deficit was observed (Williams et al., 2007). Williams et al. addressed this issue by suggesting possibility that the results reflect differences in hippocampal development concurrent with the exposure period used in their study (see Rice \& Barone, 2000, for additional discussion on this issue).

The timing of exposure during the development of an organism is an important consideration. As a case in point, in a consideration of 5-HT turnover in the nucleus accumbens of rats (Teicher, 1999), levels were four times lower in adolescent rats measured during PND 3040 than either older rats (PND 60-80) or prepubescent rats (PND 10-15). In addition, just before the onset of adolescence, $5-\mathrm{HT}_{2 \mathrm{~A}}$ receptors achieve their highest level of expression in the cortex, followed by a decline to adult levels (Morilak \& Ciaranello, 1993). Thus, the timing of MDMA and/or 5-MeO-DIPT exposure could have a variety of effects, with the long-term consequences partially influenced by both the exposure period and the length of exposure. Further, although not considered in the present study, adolescent sex-related differences associated with the effects of repeated MDMA exposure may very well be an important variable worthy of further 
consideration (Koenig et al., 2005). Past research has indicated that there appear to be sex differences in the consequences associated with MDMA use in rats (e.g., Koenig et al., 2005; Piper \& Meyer, 2004). However, as Koenig et al. (2005) noted, whether these differences reflect sex-mediated differences in the pharmacokinetic or pharmacodynamics of MDMA or hormonal mediated differences is unknown.

In the present investigation as well as previous work (Compton et al., 2011; Skelton et al., 2006, 2009), the 5-MeO-DIPT appeared to produce an effect that, in some ways is similar to, although not as severe, as reports about MDMA (Skelton et al., 2006, 2009). Developmental exposure of 5-Meo-DIPT appears to produce long-term changes in learning and memory performance, although the MDMA and 5-Meo-DIPT appear to produce dissociable effects (Skelton et al., 2009). In fact, Skelton et al. suggested that some of the observed differences in the behavioral effects of the two compounds may be a direct result in whether the drugs are equipotent. Further, the question remains as whether 5-Meo-DIPT and MDMA exerts the same degree of central nervous system effects. Skelton et al.'s proposition is worthy of addition exploration. Since these effects seem to persist following a relatively long abstinence period, examination of possible permanent alterations in cognition is warranted. As such, we currently are comparing adolescent exposure of 5-Meo-DIPT with MDMA and conducting a longitudinal assessment of the effects of these compounds across the lifespan.

Again, adolescence is a period of development associated with a number of neurodevelopmental changes. Among other things, adolescence in humans is associated with high levels of sensation-seeking behavior and a desire for novelty (Adriani \& Laviola, 2004). However, in addition to the reported learning, memory, impulsivity, and cognitive impairments described here and elsewhere (e.g., Compton et al., 2011; Green et al., 2003; Skelton et al., 2006, 2009) the use of these drugs appears to carry a number of inherent risks. For example, among the reported long-term consequences associated with the use of MDMA are nonmemorial (e.g., Parkinson's Disease; Morton, 2005) deficits. Because of the serotoninergic and possible dopaminergic properties of MDMA and 5-MeO-DIPT (Nakagawa \& Kaneko, 2007) and the fact that both are considered desirable designer drugs in the adolescent community, further research is indicated.

The results reported here provide convincing evidence that the consequences of the use of 5-MeODIPT include but, are not necessarily limited to, longterm deleterious effects on learning and memory. As noted earlier, during adolescence, a number of areas of the brain are undergoing developmental changes. Higher levels of novelty and sensation-seeking are considered common in adolescence (Adriani \& Laviola, 2004). Because of the serotoninergic and possible dopaminergic properties of 5-MeO-DIPT, these designer drugs should be examined in greater detail, especially among a teenage population at risk for the possible consequences associated with the use of 5-MeO-DIPT.

\section{Acknowledgments}

This research was sponsored in part by a grant from the Palm Beach Atlantic University Faculty Research Committee to David M. Compton. The authors would like to thank Lana Lander for her comments on an earlier draft of the manuscript and B. Gonzalez for her assistance with HPLC assessment of 5-HT.

\section{References}

Able, J. A., Gudelsky, G. A., Vorhees, C. V., \& Williams, M. T. (2006). 3,4-Methylenedioxymethamphetamine in adult rats produces deficits in path integration and spatial reference memory. Biological Psychiatry, 59, 1219-1226.

Adriani, W., \& Laviola, G. (2004). Windows of vulnerability to psychopathology and therapeutic strategy in the adolescent rodent model. Behavioral Pharmacology, 15, 341-352.

Arias-Cavieres, A., Rozas, C., Reyes-Parada, M., Barrera, N., Pancetti, F., Loyola, S., ...Morales, B. (2010). MDMA ("ecstasy") impairs learning in the Morris Water Maze and reduces hippocampal LTP in young rats. Neuroscience Letters, 469, 375-379.

Battaglia, G., Yeh, S. Y., \& De Souza, E. B. (1988). MDMA-induced neurotoxicity: parameters of degeneration and recovery of brain serotonin neurons, Pharmacology, Biochemistry, \& Behavior, 29, 269-274.

Battaglia, G., Yeh, S. Y., O’Hearn, E., Molliver, M. E., Kuhar, M. J., \& De Souza, E. B. (1987). 3,4-Methylenedioxymethamphetamine and 3,4-methylenedioxyamphetamine destroy serotonin terminals in rat brain: quantification of neurodegeneration by measurement of [3H]paroxetine-labeled serotonin uptake sites. Journal of Pharmacology and Experimental Therapeutics, 242, 911-916.

Borg, J., Henningsson, S., Saijo, T., Inoue, M., Bah, J., Westberg, L., ... Farde, L. (2009). Serotonin transporter genotype is associated with cognitive performance but not regional 5-HT1A receptor binding in humans. International Journal of Neuropsychopharmacology, $12,783-792$.

Buhot, M. C., Martin, S., \& Segu, L. (2000). Role of serotonin in memory impairment. Annuals of Medicine, 32, 210-221.

BZP and other piperazines. (updated 2010). In The European Monitoring Centre for Drugs and Drug Addiction. Retrieved from http://www.emcdda.europa.eu/publications/drug-profiles/bzp

Chapin, D.S., Lookingland, K.J., \& Moore, K. E. (1994). Effects of LC mobile phase composition on retention times for biogenic amines, and their precursors and metabolites. Current Separations, 7, 68-70.

Clarke, H. F., Dalley, J. W., Crofts, H. S., Robbins, T. W., \& Roberts, A. C. (2004). Cognitive inflexibility after prefrontal serotonin depletion. Science, 304, 878-880.

Clarke, H. F., Walker, S. C., Crofts H. S., Dalley, J. W., Robbins, T. W., \& Roberts, A. C. (2005). Prefrontal serotonin depletion affects reversal learning but not attentional set shifting. Journal of Neuroscience, 25, 532-538.

Clarke, H. F., Robbins, T. W., \& Roberts, A. C. (2008). Lesions of the medial striatum inmonkeys produce perseverative impairments during reversal learning similar to those produced by lesions of the orbitofrontal cortex. Journal of Neuroscience, 28, 10972-10982.

Clemens, K. J., Cornish, J. L., Hunt, G. E., \& McGregor, I. S. (2007). Repeated weekly exposure to MDMA, methamphetamine or their combination: Long-term behavioural and neurochemical effects in rats. Drug and Alcohol Dependence, 86, 183-190.

Cohen, N. J., \& Eichenbaum H. (1993). Memory, amnesia, and the hippocampal system. Cambridge, MA: MIT.

Compton, D. M. (2001). Are memories for stimulus-stimulus associations or stimulus-response associations responsible for 
serial-pattern learning in rats? Physiology \& Behavior, 72, 643-652.

Compton, D. M., Dietrich, K. L., Selinger, M. C., \& Testa, E. K. (2011). 5-Methoxy-N,N-di(iso)propyltryptamine hydrochloride (Foxy)induced cognitive deficits in rat after exposure in adolescence. Physiology \& Behavior, 103, 203-209.

Compton, D. M., Selinger, M. C., Testa, E. K., \& Larkins, K. D. (2006). An examination of the effects of 5-methoxy-N, $\mathrm{N}$-diisopropyltryptamine hydrochloride (Foxy) on cognitive development in rats. Psychological Reports, 98, 651-661.

Compton, D. M., Dietrich, K. L., \& Smith, J. S. (1997). Enhancement of spatial navigationability in older rats following chronic administration of the alpha noradrenergic antagonist piperoxane. Psychological Record, 47, 321-334.

De Souza, E. B., Battaglia, G., \& Insel, T. R. (1990). Neurotoxic effect of MDMA on brain serotonin neurons: evidence from neurochemical and radioligand binding studies. Annals of the New York Academy of Science, 600, 682-697, (discussion 697-698).

Drugs and chemicals of concern. 5-methoxy-n,n-diisopropyltryptamine. (June, 2009). Retrieved from http://www.deadiversion.usdoj.gov/ drugs concern $/ 5$ meodipt.htm.

Eichenbaum, H., Stewart, C., \& Morris, R. G. M. (1991). Hippocampal representation in place learning. Journal of Neuroscience, 10, 3531-3542.

Fellows, B. J. (1967). Chance stimulus sequences for discrimination trials. Psychological Bulletin, 67, 87-92.

Fischer, C., Hatzidimitriou, G., Wlos, J. Katz, \& Ricaurte, G. (1995). Reorganization of ascending 5-HT axon projections in animals previously exposed to the recreational drug (+/-)3,4-methylenedioxymethamphetamine (MDMA, 'ecstasy'). Journal of Neuroscience, 15, 5476-5485.

Fox, H. C., McLean, A., Turner, J. J. D., Parrott, A. C., Rogers, R., \& Sahakian, B. J. (2002). Neuropsychological evidence of a relatively selective profile of temporal dysfunction in drug-free MDMA ("ecstasy") polydrug users. Psychopharmacology, 162, 203-214.

Fox, H. C., Toplis, A. S., Turner, J. J. D., \& Parrott, A. C. (2001). Auditory verbal learning in drug-free ecstasy polydrug users. Human Pharmacology: Clinical Experimental, 16, 613-618.

Green, A. R., Mechan, A. O., Elliott, J. M., O'Shea, E., \& Colado, M. I. (2003). The pharmacology and clinical pharmacology of 3,4-methylenedioxymethamphetamine (MDMA, "ecstasy"). Pharmacological Reviews, 55, 463-508.

Gouzoulis-Mayfrank, E., Thimm, B., Rezk, M., Hensen, G., \& Daumann, J. (2003). Memory impairment suggests hippocampal dysfunction in abstinent ecstasy users. Progress in NeuroPsychopharmacology and Biological Psychiatry, 27, 819-827.

Harper, D. N., Wisnewski, R., Hunt, M., \& Schenk, S. (2005). (+)3,4-Methylenedioxymethamphetamine, d-Amphetamine, and cocaine impair delayed matching-to-sample performance by an increase in susceptibility to proactive interference. Behavioral Neuroscience, 119, 455-463.

Harrison, A. A., Everitt, B.J., \& Robbins, T. W. (1997). Central 5-HT depletion enhances impulsive responding without affecting the accuracy of attentional performance: interactions with dopamine mechanisms. Psychopharmacology, 133, 329-342.

Hatzidimitriou, G., McCann, U. D., \& Ricaurte, G. A. (1999). Altered serotonin innervation patterns in the forebrain of monkeys treated with (+/-)3,4-methylenedioxymethamphetamine seven years previously: Factors influencing abnormal recovery. Journal of Neuroscience, 19, 5096-5107.

Heffernan, T. M., Jarvis, H., Rodgers, J., Scholey, A. B., \& Ling, J. (2001). Prospective memory, everyday memory failure and central executive function in recreational users of ecstasy. Human Psychopharmacology, 16, 607-612.

Heffernan, T. M., Ling, J., \& Scholey, A. B. (2001). Subjective ratings of prospective memory deficits in MDMA ('ecstasy') users. Human Psychopharmacology, 16, 339-344.

Ikeda, A., Sekiguchi, K., Fujita, K., Yamadera, H., \& Kog, Y. (2005). 5 -methoxy-N,N-diisopropyltryptamine-induced flashbacks. American Journal of Psychiatry, 162, 815.

Kalant, H. (2001). The pharmacology and toxicology of "ecstasy" (MDMA) and related drugs. Journal of the Canadian Medical Association, 165, 917-928.

Kalueff, A. V., Olivier, J. D. A., Nonkes, L. J. P., \& Homberg, J. R. (2010). Conserved role for the serotonin transporter gene in rat and mouse neurobehavioral endophenotypes. Neuroscience and Biobehavioral Reviews, 34, 373-86.
Kanamori T., Kuwayama K., Tsujikawa K., Miyaguchi H., \& Kishi T. (2006). In vivo metabolism of 5-methoxy- $N, N$-diisopropyltryptamine in rat. Journal of Health Science, 52, 425-430.

Kay, C., Harper, D. N., \& Hunt, M. (2010). Differential effects of MDMA and scopolamine on working versus reference memory in the radial arm maze task. Neurobiology of Learning and Memory, 93, 151-156.

Kay, C., Harper, D. N., \& Hunt, M. (2011). The effects of binge MDMA on acquisition andreversal learning in a radial-arm maze task. Neurobiology of Learning and Memory, in press.

Kelly, P.A., Ritchie, I. M., Quate, L., McBean, D. E., \& Olverman, H. J. (2002). Functional consequences of perinatal exposure to 3,4-methylenedioxymethamphetamine in rat brain. British Journal of Pharmacology, 137, 963-970.

Kesner, R. P., DiMattia, B. V., \& Crutcher, K. A. (1987). Evidence for neocortical involvement in reference memory, Behavioral and Neural Biology, 47, 40-53

Koenig, J., Lazarus, C., Jeltsch, H., Ben Hamida, S., Riegert, C., Kelche, C., Jones, B. C., \& Cassel, J.-C. (2005). MDMA (ecstasy) effects in pubescent rats: Males are more sensitive than females. Pharmacology, Biochemistry \& Behavior, 81, 635-644.

Kolb, B., \& Whishaw, I. Q. (2003). Fundamentals of human neuropsychology (5th ed.). NewYork: Worth.

Koprich, J. B., Chen, E. Y., Kanaan, N. M., Campbell, N. G., Kordower, J. H., \& Lipton, J. W.(2003). Prenatal 3,4-methylenedioxymethamphetamine (ecstasy) alters exploratory behavior, reduces monoamine metabolism, and increases forebrain tyrosine hydroxylase fiber density of juvenile rats. Neurotoxicology and Teratology, 25, 509-517.

Lew, R., Sabol, K. E., Chou, C., Vosmer, G. L., Richards, J., \& Seiden, L. S. (1996). Methylenedioxymethamphetamine-induced serotonin deficits are followed by partial recovery over a 52 -week period. Part II: radioligand binding and autoradiography studies. Journal of Pharmacology and Experimental Therapeutics, 276, 855-865.

Linnoila, M., Virkkunen, M., Scheinin. M., Nuutila. A., Rimon, R., \& Goodwin, FK. (1983). Low cerebrospinal fluid 5-hydroxyindoleacetic acid concentration differentiates impulsive from nonimpulsive violent behavior. Life Sciences, 33, 2609-2614.

Lyles, J., \& Cadet, J. L. (2003). Methylenedioxymethamphetamine (MDMA, Ecstasy) neurotoxicity: cellular and molecular mechanisms. Brain Research Reviews, 42, 155-168.

Mas, M., Farré, M., De La Torre, R., Roset, P. N., Ortuño, J., Segura, J., \& Camí, J. (1999). Cardiovascular and neuroendocrine effects and pharmacokinetics of 3,4-methylenedioxymethamphetamine in humans. Journal of Pharmacology and Experimental Therapeutics, 290, 136-145.

McCardle, K., Luebbers, S., Carter, J. D., Croft, R. J., \& Stough, C. (2004). Chronic MDMA (ecstasy) use, cognition and mood. Psychopharmacology (Berlin), 173, 434-439.

Marston, H. M., Reid, M. E., Lawrence, J. A., Olverman, H.J., \& Butcher, S. P. (1999). Behavioural analysis of the acute and chronic effects of MDMA treatment in the rat. Psychopharmacology (Berlin), 144, 67-76

McDaniel, W. F., Via, J. D., Smith, J. S., Wells, D. L., Fu, J. J., Bishop, J. F., Boyd, P. A. , \& Ledesma, H. M. (1995). Unilateral injury of posterior parietal cortex and spatial learning in hooded rats. Behavioural Brain Research, 70, 165-179.

Meatherall, R., \& Sharma, P. (2003). Foxy, a designer tryptamine hallucinogen. Journal of Analytic Toxicology, 27, 313-317.

Morilak, D. A., \& Ciaranello, R. D. (1993). Ontogeny of 5-hydroxytryptamine2 receptor immunoreactivity in the developing rat brain. Neuroscience, 55, 869-880.

Morton, J. (2005). Ecstasy: pharmacology and neurotoxicity. Current Opinion in Pharmacology 5, 79-86.

Moyano, S., Frechilla, D., \& Del Rio, J. (2004). NMDA receptor subunit and CaMKII changes in rat hippocampus induced by acute MDMA treatment: a mechanism for learning impairment. Psychopharmacology (Berlin), 173, 337-345.

Murphy, D. L., Fox, M. A., Timpano, K. R., Moya, P. R., Ren-Patterson, R., Andrews, A. M., ... Wendland, J. R. (2008). How the serotonin story is being rewritten by new gene-based discoveries principally related to SLC6A4, the serotonin transporter gene, which functions to influence all cellular serotonin systems. Neuropharmacology, $55,932-960$

Nagai, F., Nonaka, R., \& Hisashi, K. K. S. (2007). The effects of nonmedicinally used psychoactive drugs on monoamine 
neurotransmission in rat brain. European Journal of Pharmacology, 559, 132-137.

Nakagawa, T., \& Kaneko, S. (2008). Neuropsychotoxicity of abused drugs: molecular and neural mechanisms of neurotoxicity induced by methamphetamine, 3,4-methylenedioxymethamphetamine (ecstasy), and 5-methoxy-N,N-diisopropyltryptamine (foxy). Journal of Pharmacological Sciences, 106, 2-8.

National Research Council. (1996). Guide for the Care and Use of Laboratory Animals. Washington, DC: National Academic Press.

Olivier, J., Cools, A., Ellenbroek, B., Cuppen, E., \& Homberg, J. (2010). The serotonin transporter knockout rat: a review. In A. V. Kalueff \& J. L. LaPorte (Eds.), Experimental models in serotonin transporter research (pp. 170-213). Cambridge, UK: Cambridge University Press.

Oreland L. (1993). Monoamine oxidase in neuro-psychiatric disorders. In H. Yasuhara, S. H. Parvez, K. Oguchi, M. Sandler, \& T. Nagatsu (Eds.), Monoamine oxidase: basic and clinical aspects (pp. 219247). Utrecht, Netherlands: VSP.

Parrott, A. C. (2002). Recreational Ecstasy/MDMA, the serotonin syndrome, and serotonergic neurotoxicity. Pharmacology, Biochemistry, and Behavior, 71, 837-44.

Parrott, A. C., \& Lasky, J. (1998). Ecstasy (MDMA) effects upon mood and cognition: Before, during and after a Saturday night dance. Psychopharmacology, 139, 261-268.

Pettenuzzo, L. F., Wyse, A. T. S., Wannamacher, C. M. D., DutraFilho, C. S., Netto, C. A., \& Wajner, M. (2003). Evaluation of chronic administration of drugs on rat behavior in the water maze. Brain Research Protocols, 12, 109-115.

Piper, B. J., \& Meyer, J. S. (2004). Memory deficit and reduced anxiety in young adult rats given repeated intermittent MDMA treatment during the periadolescent period. Pharmacology, Biochemistry, \& Behavior, 79, 723-731.

Rice, D., \& Barone, S. Jr. (2000). Critical periods of vulnerability for the developing nervous system: Evidence from humans and animal models. Environmental Health Perspectives, 108, 511-533.

Sabol, K. E., Lew, R., Richards, J. B., Vosmer, G. L., \& Seiden, L. S. (1996). Methylenedioxymethamphetamine-induced serotonin deficits are followed by partial recovery over a 52 -week period. Part I: Synaptosomal uptake and tissue concentrations. Journal of Pharmacology and Experimental Therapeutics, 276, 846-854.

Scanzello, C. R., Hatzdimitriou, G., Martello, A. L., Katz, J. L., \& Ricuarte, G. A. (1993). Response of central serotonergic neurons to ( \pm )3,4-methylenedioxymethamphetamine (MDMA) injury: Observations in rats. Journal of Pharmacology and Experimental Therapeutics, 264, 1484-1491.

Schmidt, C. J. (1987). Neurotoxicity of the psychedelic amphetamine, methylenedioxymethamphetamine, Journal of Pharmacology and Experimental Therapeutics, 240, 1-7.

Seiden, L. S., Lew, R., \& Malberg J. E. (2002). Neurotoxicity of methamphetamine and methylenedioxymethamphetamine. Neurotoxicity Research, 3, 101-116.

Sitaram, B. R., Lockett, G. L., \& Blackman, W. R. (1987). Urinary excretion of 5-methoxy- $N, N$ dimethyltryptamine, $N, N$ dimethyltryptamine and their N-oxides in the rat. Biochemical Pharmacology, 36, 2235-2237.

Shanahan, N. A., Holick Pierz, K. A., Masten, V. L., Waeber, C., Ansorge, M., Gingrich, J. A., ... Dulawa, S. C. (2009). Chronic reductions in serotonin transporter function prevent 5-HT1B-induced behavioral effects in mice. Biological Psychiatry, 65, 401-408.

Shulgrin A., \& Carter, M. F. (1980). N,N-Diisopropyltryptamine (DIPT) and 5-methoxy- $N, N$-diisopropyltryptamine (5-MeODIPT). Two orally active tryptamine analogs with CNS activity. Communications in Psychopharmacology, 4, 363-369.

Skelton, M. R., Williams, M. T., \& Vorhees, C. V. (2006). Treatment with MDMA from P11-20 disrupts spatial learning and path integration learning in adolescent rats but only spatial learning in older rats. Psychopharmacology (Berlin), 189, 307-318.

Skelton, M. R., Able, J. A., Grace, C. E., Herring, N. R., Schaefer, T. L., Gudelsky, G. A., Vorhees, C. V., \& Williams, M. T. (2008). $( \pm)$-3,4-methylenedioxymethamphetamine treatment in adult rats impairs path integration learning: A comparison of single vs once per week treatment for 5 weeks. Neuropharmacology, 55, 1121-1130.

Skelton, M. R., Schaefer, T. L., Herring, N. R., Grace, C. E., Vorhees, C. V., \& Williams, M. T. (2009). Comparison of the developmental effects of 5-methoxy- $N, N$-diisopropyltryptamine (Foxy) to $( \pm)$-3,4-methylenedisoxymethamphetamine (ecstasy) in rats.
Psychopharmacology, 204, 287-297.

Slikker Jr., W., Ali, S. F., Scallet, A. C., Frith, C. H., Newport, G. D., \& Bailey, J. R. (1988). Neurochemical and neurohistological alterations in the rat and monkey produced by orally administered methylenedioxymethamphetamine (MDMA), Toxicology \& Applied Pharmacology, 94, 448-457.

Smolinske, S., Rastogi, R., \& Schenkel, S. (2003). Foxy methoxy: A new drug of abuse. Journal of Toxicology-Clinical Toxicology, 41, 641.

Soderpalm, B., \& Svensson, A. I. (1999). Naloxone reverses disinhibitory/aggressive behavior in 5,7-DHT-lesioned rats; involvement of GABA(A) receptor blockade? Neuropharmacology, $38,1851-1859$.

Sogawa, C., Sogawa, N., Tagawac, J., Fujino, A., Ohyama, K., Asanumad, M., Funada, M., \& Kitayama, S. (2007). 5-Methoxy$N, N$-diisopropyltryptamine (Foxy), a selective and high affinity inhibitor of serotonin transporter. Toxicology Letters, 170, 75-82.

Soubrie', P. (1986). Reconciling the role of central serotonin neurons in human and animal behavior. Behavioral and Brain Sciences, 9, 319-364.

Spear, L. P. (2000). The adolescent brain and age-related behavioral manifestations. Neuroscience and Biobehavioral Reviews, 24, 417-463.

Sprague, J. E., Preston, A. S., Leifheit, M., \& Woodside, B. (2003). Hippocampal serotonergic damage induced by MDMA (ecstasy): Effects on spatial learning. Physiology \& Behavior, 79, 281-287.

Squire, L. R., Bloom, F. E., McConnell, S. K, Roberts, J. L., Spitzer, N. C., \& Zigmond, M. J. (2003). Fundamental neuroscience $\left(2^{\text {nd }}\right.$ Ed.). San Diego, CA: Academic.

Teicher, M. H. (1999). Limbic serotonin turnover plunges during puberty. Poster presented at the Meeting of the Society for Neuroscience, Miami Beach, FL.

Thompson, V. B., Heiman, J., Chambers, J. B., Benoit, S. C., Buesing, W. R., Norman, M. K., Norman, A. B., \& Lipton, J. W. (2009). Long-term behavioral consequences of prenatal MDMA exposure. Physiology \& Behavior, 69, 593-601.

Tirelli, E., Laviola, G., \& Adriani, W. (2000). Ontogenesis of behavioral sensitization and conditioned place preference in laboratory rodents. Neuroscience and Biobehavioral Reviews, 23, 163-178.

United States Drug Enforcement Administration (2003). Schedules of controlled substances: Temporary placement of alphamethyltryptamine and 5-methoxy-,Ndiisopropyltryptamine into Schedule I. Final rule. Federal Register, 68(65), 16427-16430.

Uylings, H. B. M., Groenewegen, H. J., \& Kolb, B. (2003). Do rats have a prefrontal cortex?Behavioural Brain Research, 146, 3-17.

Verebey, K., Alrazi, J., \& Jaffe, J. H. (1988). The complications of 'ecstasy' (MDMA). Journal of the American Medical Association, 259, 1649-1650.

Vorhees, C. V., Reed, T. M., Skelton, M. R., \& Williams, M. T. (2004). Exposure to 3,4-methylenedioxymethamphetamine (MDMA) on postnatal days 11-20 induces reference but not working memory deficits in the Morris water maze in rats: implications of prior learning. International Journal of Developmental Neuroscience, $22,247-259$.

Vorhees, C. V., Schaefer, T. L., \& Williams, M. T. (2007). Developmental effects of \pm - methylenedioxymethamphetamine (MDMA) on spatial vs. path integration learning: Effects of dose distribution. Synapse, 61, 488-499.

Vorhees, C. V., Schaefer, T. L., Skelton, M. R., Grace, C. E., Herring, N. R., \& Williams, M. T. (2009). (+/-)3,4-Methylenedioxymethamphetamine (MDMA) dosedependently impairs spatial learning in the Morris Water Maze after exposure of rats to different five-day intervals from birth to postnatal day twenty. Developmental Neuroscience, 31, 107-120.

Wareing M., Fisk J. E., \& Murphy, P. N. (2000). Working memory deficits in current and previous users of MDMA ("ecstasy"). British Journal of Psychology, 91, 181-188.

Wareing, M., Murphy, P., \& Fisk, J. E. (2004). Visuospatial memory impairments in users of MDMA ('ecstasy'). Psychopharmacology, 173, 391-397.

Williams, M. T., Herring, N. R., Schaefer, T. L., Skelton, M. R., Campbell, N. G., Lipton, J. W., McCrea, A. E., \& Vorhees, C. V. (2007). Alterations in body temperature, corticosterone, and behavior following the administration of 5-methoxydiisopropyltryptamine ('Foxy') to adult rats: a new drug of abuse. Neuropsychopharmacology, 32, 1401-1420. 
Wilson, J. M., McGeorge, F., Smolinske, S., \& Meatherall, R. (2005). A foxy intoxication. Forensic Science International, 148, 31-36.

World Drug Report 2010. (2010). Vienna, Austria: United Nations
Office on Drugs and Crime.

Zakzanis, K. K., \& Campbell, Z. (2006). Memory impairment in now abstinent MDMA users and continued users: A longitudinal followup. Neurology, 66, 740-741. 